\title{
Exacerbation of sleep-apnoea related nocturnal blood-pressure fluctuations in hypertensive subjects
}

\author{
C. Planès*, M. Leroy*, G. Fayet*, P. Aegerter*, A. Foucher*, B. Raffestin*
}

Exacerbation of sleep-apnoea related nocturnal blood-pressure fluctuations in hypertensive subjects. C. Planès, M. Leroy, G. Fayet, P. Aegerter, A. Foucher, B. Raffestin. (C) ERS Journals Ltd 2002.

ABSTRACT: Obstructive sleep apnoea syndrome (OSAS) induces marked haemodynamic fluctuations during sleep that might be deleterious to the cardiovascular system. The influence of daytime blood pressure (BP) levels and aging on short-term BP variability during sleep in OSAS patients was investigated.

Twenty-nine subjects with newly-diagnosed untreated OSAS were categorised into three groups: normotensive subjects aged $<\mathbf{5 0}$ yrs $(\mathbf{n}=\mathbf{1 0})$; subjects aged $<\mathbf{5 0}$ yrs with untreated hypertension $(n=8)$; and normotensive subjects aged $>50$ yrs $(n=11)$. Beat-bybeat BP was recorded with a Finapres device during polysomnography. The average values \pm SD of apnoea-related $B P$ elevations and the values of the frequency distribution of all BP variations during sleep were assessed to estimate short-term BP variability.

Apnoea-related systolic (or diastolic) BP elevations were significantly greater in hypertensives than in normotensives aged $<50$ yrs $(50.3 \pm 4.88$ versus $30.7 \pm 2.14 \mathrm{mmHg}$, $p<0.001$ ), as was the SD of systolic (or diastolic) BP variations during sleep (I9.6 \pm 2.22 versus $11.1 \pm 0.73, p<0.001)$. Short-term $B P$ variability was not significantly increased in normotensive elderly patients.

To conclude, the results suggested that systemic hypertension is associated with a greater exacerbation of short-term variability during sleep in obstructive sleep apnoea syndrome patients.

Eur Respir J 2002; 20: 151-157.
*Service d'Exploration Fonctionnelle Multidisciplinaire and ${ }^{\#}$ Département de Biostatistiques Hôpital Ambroise Paré (Assistance Publique - Hôpitaux de Paris) Université Paris, Boulogne, France.

Correspondence: C. Planès

Service d'Exploration Fonctionnelle

Hôpital Ambroise Pare

92104 Boulogne

Cedex France

Fax: 33149095906

E-mail: carole.planes@apr.ap-hop-paris.fr

Keywords: Aging

blood pressure

sleep

sleep apnoea syndrome

Received: August 302001

Accepted after revision: January 29 2002
Systemic hypertension (HT) is highly prevalent in patients with obstructive sleep apnoea syndrome (OSAS) [1], and recent epidemiological studies [2-4] suggest that this association is not entirely explained by known confounding factors such as obesity, age and sex. It has been speculated that the cardiovascular morbidity of OSAS may, in part, be related to the oscillations in systemic blood pressure (BP) and increases in sympathetic discharges that occur repeatedly during the night $[5,6]$. Indeed, BP falls in time with inspiratory efforts at the beginning of each obstructive episode and rises abruptly at apnoea termination, reaching a peak during the first postapnoeic breaths. Moreover, whereas in normal subjects sympathetic activity decreases during the night, measurements with microneurographical techniques have shown a progressive increase in sympathetic nerve activity during obstructive apnoea with a peak near the end of apnoea $[5,7]$. Consequently, the significant decrease in the level and variability of BP normally observed during nonrapid eye movement (NREM) sleep is blunted in OSAS patients [7].

In subjects with untreated essential HT, arterial baroreceptor reflex operates at higher pressures and baroreceptor heart-rate reflex has been reported to be decreased [8]. The resulting increase in short-term variability of BP may play a role in the alteration of function and structure of the cardiovascular system, since in subjects with untreated systemic HT, targetorgan damage has been shown to be related not only to the level of 24-h mean intraarterial BP, but also to $\mathrm{BP}$ variability $[9,10]$. As nocturnal $\mathrm{BP}$ variability has been reported to be increased in patients with essential systemic HT, it led the authors to consider whether the association of systemic HT with OSAS could exacerbate the fluctuations of BP related to apnoeic episodes.

To address this question and examine the effect of age, which has been shown to be associated with an increase in sympathetic nerve activity [11], the BP variability during sleep of three groups of subjects with OSAS was compared using a prospective study. The three groups included: subjects aged $<50$ yrs with normal daytime BP; subjects aged $<50$ yrs with untreated daytime systemic HT; and subjects aged $>50$ yrs with normal daytime BP. Using a photoplethysmographic device (Finapres; Ohmeda Inc., Englewood, NJ, USA) to record beat-to-beat BP, the amplitude of apnoea-related BP elevations measured manually were first averaged, and then the short-term 
variability of nocturnal BP was assessed by computing the SD of the distribution of BP variations according to their amplitude [12].

\section{Material and methods}

\section{Study subjects}

During a period of 18 months, 29 patients referred consecutively to the sleep laboratory for clinical suspicion of OSAS were recruited according to the following criteria: 1) newly-diagnosed OSAS defined as an apnoea/hypopnoea index (AHI) of $>15 \mathrm{~h}$ of sleep on nocturnal polysomnography; 2) no previous cardiovascular treatment or treatment stopped for $\geqslant 3$ weeks; 3) no symptoms of cardiac failure or arrhythmia; and 4) no previous treatment by hypnotic drugs or treatment stopped for $\geqslant 3$ weeks. The patients were divided into the following three groups according to their age and their daytime BP measured with a sphygmomanometer on three separate occasions. Group 1: patients aged $<50$ yrs without systemic HT (defined as systolic BP (SBP) $\geqslant 140 \mathrm{mmHg}$, diastolic BP (DBP) $\geqslant 90 \mathrm{mmHg})(\mathrm{n}=10)$; group 2: patients aged $<50$ yrs with untreated systemic HT $(n=8)$; group 3 : patients aged $>50$ yrs without systemic HT $(n=11)$. Among the eight subjects in group 2, two had stage 1 hypertension $(140 \leqslant \mathrm{SBP}<159 \mathrm{mmHg}$ or $90 \leqslant \mathrm{DBP}<99 \mathrm{mmHg})$, three had stage 2 hypertension $(160 \leqslant \mathrm{SBP}<179 \mathrm{mmHg}$ or $100 \leqslant \mathrm{DBP}<109 \mathrm{mmHg}$ ) and three had stage 3 hypertension $(\mathrm{SBP} \geqslant 180 \mathrm{mmHg}$ or $\mathrm{DBP} \geqslant 110 \mathrm{mmHg}$ ) according to the classification of the World Health Organization. Clinical characteristics of the subjects are given in table 1.

\section{Study design}

All patients were studied using overnight polysomnography in the sleep laboratory and nocturnal BP was monitored simultaneously using a Finapres device (Ohmeda Inc.). Average values of BP elevations at the end of apnoea were determined, and BP variability during sleep was estimated for comparison between groups.
Polysomnography. The polysomnographic data were recorded with a 16-channel polygraph (Reega 2000, Alvar, Paris, France), as previously described [12]. Sleep staging was performed according to the criteria of RECHTSCHAFFEN and KALES [13]. Electroencephalographic (EEG) arousals were scored according to standard criteria of the American Sleep Disorder Association (ASDA) [14]. Apnoea was defined as cessation of oronasal airflow for $>10 \mathrm{~s}$ and hypopnoea as a reduction of oronasal airflow to $\geqslant 50 \%$ of the value prevailing during preceding normal breathing for $\geqslant 10 \mathrm{~s}$ followed by transient EEG arousal.

Recording blood pressure during polysomnography. Beat-by-beat photoplethysmographic BP was monitored continuously with Finapres, with the exception of 10-min periods every $2 \mathrm{~h}$ where the system was turned off for patient comfort [12]. All systolic and diastolic BP values as well as pulse oximetry values (Criticare 504, Critcare Systems Inc., Waukeste, WI, USA; averaging time: $3 \mathrm{~s}$ ) were synchronised with polysomnography and analysed on a personal computer using software developed by the authors.

\section{Results}

Measurement of blood pressure elevations associated with apnoeas. For every patient, 30 apnoeic/hypopnoeic events ending with a typical EEG arousal were randomly selected using random number tables during sleep stages 1 or 2 , and the corresponding SBP and DBP elevations were measured manually. SBP (DBP) elevation was the difference between the highest value (peak) of SBP (DBP) recorded during the 10-s period immediately following the end of apnoea and the lowest value (nadir) of SBP (DBP) recorded during the 10-s period immediately preceding the end of apnoea. The minimal arterial oxygen saturation $\left(\mathrm{Sa}_{\mathrm{a}} \mathrm{O}_{2}\right)$ and the degree of desaturation $\left(\Delta S_{\mathrm{a}}, \mathrm{O}_{2}\right)$ at the termination of every selected event were noted, as well as the event duration.

\section{Statistical analysis}

Results are expressed as means \pm SEM. Between-group comparisons were performed using a Kruskal-Wallis test. When a significant difference was observed,

Table 1. - Subject characteristics

\begin{tabular}{|c|c|c|c|}
\hline & Group 1 & Group 2 & Group 3 \\
\hline & $\overline{\text { Age }<50 \text { yrs normotensive }}$ & $\overline{\text { Age }<50 \text { yrs hypertensive }}$ & $\overline{\text { Age }>50 \text { yrs normotensive }}$ \\
\hline Subjects $n$ & 10 & 8 & 11 \\
\hline Age yrs & $39.9 \pm 2.31(25-49)$ & $42.0 \pm 2.88(29-49)$ & $61.2 \pm 1.82 * * *(54-71)$ \\
\hline Body mass index $\mathrm{kg} \cdot \mathrm{m}^{-2}$ & $32.2 \pm 2.40(25-47)$ & $33.4 \pm 2.01(26-42)$ & $28.9 \pm 1.72(18-42)$ \\
\hline Davtime SBP mmHg & $126.5 \pm 2.24$ & $162.5 \pm 3.78 * * *$ & $133.6 \pm 2.13$ \\
\hline Daytime DBP $\mathrm{mmHg}$ & $78.5 \pm 2.47$ & $105.6 \pm 3.81^{* * *}$ & $82.3 \pm 1.04$ \\
\hline Sex M:F & $7: 3$ & $7: 1$ & $11: 0$ \\
\hline Smoking habits S:NS & $3: 7$ & $3: 5$ & $1: 10$ \\
\hline
\end{tabular}

Results are presented as mean \pm SEM (range). Daytime blood pressure was measured at least three times in the supine position using a sphygmomanometer. S: smoker; NS: nonsmoker; F: female; M: male; SBP: systolic blood pressure; DBP: diastolic blood pressure. $* * *: \mathrm{p}<0.001$, significantly different from group 1 . 
multiple pairwise comparisons were performed with the Bonferroni/Dunn procedure. Comparisons of percentages of total sleep time (TST) spent in stages 1-2 or with a $\mathrm{Sa}_{\mathrm{a}} \mathrm{O}_{2}$, of $<90 \%$ were performed with a Chisquared test. Relationships between variables were evaluated by a Spearman's rank correlation test. A $\mathrm{p}<0.05$ was considered statistically significant.

Polysomnography data and blood pressure values during sleep

There were no significant differences between the degree of sleep disturbance in the three groups as assessed by AHI, arousal index, sleep structure and percentage of nocturnal time spent with a $\mathrm{Sa}_{\mathrm{a}} \mathrm{O}_{2}$ of $<90 \%$, or mean $\mathrm{Sa}_{\mathrm{a}} \mathrm{O}_{2}$, during TST (table 2). Only four subjects (two from group 2 and two from group 3 ) displayed severe oxygen desaturations at the end of apnoea, with an average minimal $S \mathrm{a}, \mathrm{O}_{2}$ of $<75 \%$, and a mean $\mathrm{Sa}_{\mathrm{a}} \mathrm{O}_{2}$ during TST of $<90 \%$, while $\mathrm{Sa}, \mathrm{O}_{2}$ did not decrease $<85 \%$ in the remaining 25 subjects.

$\mathrm{BP}$ values obtained with Finapres at the beginning and end of the night were close (within $10 \mathrm{mmHg}$ ) to the values simultaneously measured with a sphygmomanometer. Nocturnal Finapres BP recordings were satisfactory in all patients (mean duration of analysis: $294 \pm 12.2 \mathrm{~min}$, representing $77 \pm 2.0 \%$ of TST), but the average values of SBP and DBP and the SD of the distribution of BP variations during sleep could not be calculated in two of the 11 subjects from group 3 because of a computer problem. As shown in figure 1, all the subjects with untreated daytime hypertension had either probable $(127<\mathrm{SBP}<137 \mathrm{mmHg}$ or $79<$ DBP $<87 \mathrm{mmHg}$ ) or definite (SBP $>137 \mathrm{mmHg}$ or
DBP $>87 \mathrm{mmHg}$ ) nocturnal hypertension according to the meta-analysis of STAESSEN et al. [15]. SBP and DBP values during sleep were significantly higher in group 2 than in group 1 or 3 , but did not differ between groups 1 and 3 (table 3 ).

\section{Apnoea-related blood pressure elevations}

The mean amplitudes of SBP (DBP) elevations at the termination of obstructive events in stages 1 or 2

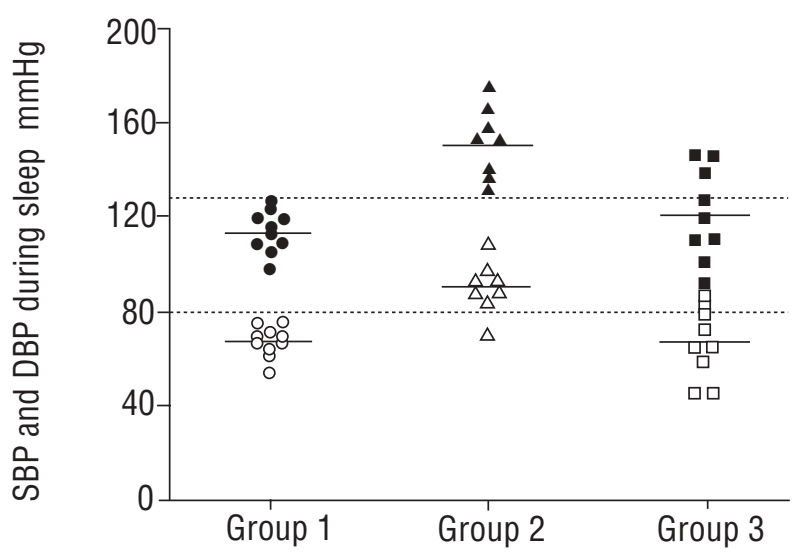

Fig. 1.- Individual values of systolic blood pressure (SBP) and diastolic blood pressure (DBP) during sleep. Data are shown for individual patients and as average values for the group as a whole. $\bullet, \boldsymbol{\Delta}, \mathbf{\square}$ : average SBP values; $\bigcirc, \triangle, \square$ : average DBP values. The higher dotted line indicates the upper limit of normal for nocturnal SBP $(127 \mathrm{mmHg})$, the lower dotted line indicates the upper limit of normal for nocturnal DBP $79 \mathrm{mmHg}$, according to the meta-analysis of STAESSENS et al. [15].

Table 2. - Polysomnography data

\begin{tabular}{|c|c|c|c|}
\hline & Group 1 & Group 2 & Group 3 \\
\hline & $\begin{array}{l}\text { Age }<50 \text { yrs } \\
\text { normotensive }\end{array}$ & $\begin{array}{l}\overline{\text { Age }<50 \text { yrs }} \\
\text { hypertensive }\end{array}$ & $\begin{array}{l}\text { Age }>50 \text { yrs } \\
\text { normotensive }\end{array}$ \\
\hline Subjects $n$ & 10 & 8 & 11 \\
\hline TST min & $\begin{array}{l}380 \pm 11.2 \\
(304-408)\end{array}$ & $\begin{array}{l}415 \pm 10.5 \\
(383-464)\end{array}$ & $\begin{array}{l}351 \pm 28.8 \\
(180-448)\end{array}$ \\
\hline Time spent in stages $1-2 \% \mathrm{TST}$ & $\begin{array}{c}76.0 \pm 3.82 \\
(55-94)\end{array}$ & $\begin{array}{l}73.6 \pm 3.75 \\
(56-87)\end{array}$ & $\begin{array}{c}78.6 \pm 4.15 \\
(60-99)\end{array}$ \\
\hline Apnoea/hypopnoea index events $\cdot h^{-1}$ & $\begin{array}{l}45.5 \pm 4.14 \\
(19-92)\end{array}$ & $\begin{array}{l}55.4 \pm 7.46 \\
(35-89)\end{array}$ & $\begin{array}{l}54.5 \pm 4.53 \\
(26-88)\end{array}$ \\
\hline Arousal index events $\cdot h^{-1}$ & $\begin{array}{c}30.4 \pm 3.19 \\
(14-41)\end{array}$ & $\begin{array}{l}28.8 \pm 4.81 \\
\quad(7-46)\end{array}$ & $\begin{array}{l}32.8 \pm 4.96 \\
(16-65)\end{array}$ \\
\hline Time with $\mathrm{Sa}_{\mathrm{a}, \mathrm{O}_{2}}<90 \% \% \mathrm{TST}$ & $\begin{array}{c}6.5 \pm 2.23 \\
(0-20)\end{array}$ & $\begin{array}{l}23.4 \pm 9.36 \\
\quad(1-77)\end{array}$ & $\begin{array}{l}16.0 \pm 6.14 \\
(0-67)\end{array}$ \\
\hline Mean $S_{\mathrm{a}, \mathrm{O}_{2}}$ during sleep $\%$ & $\begin{array}{l}94.5 \pm 0.41 \\
(92.2-96.1)\end{array}$ & $\begin{array}{l}90.6 \pm 2.12 \\
(77.6-94.9)\end{array}$ & $\begin{array}{l}92.0 \pm 1.11 \\
(82.1-94.9)\end{array}$ \\
\hline $\mathrm{Sa}_{\mathrm{a}, \mathrm{O}_{2}}$ nadir during apnoeas (stages $\left.1-2\right) \%$ & $\begin{array}{l}91.2 \pm 1.01 \\
(86.5-95.3)\end{array}$ & $\begin{array}{l}85.7 \pm 3.18 \\
(71.5-94.7)\end{array}$ & $\begin{array}{l}87.1 \pm 2.26 \\
(71-94.6)\end{array}$ \\
\hline$\Delta S_{\mathrm{a}, \mathrm{O}_{2}}$ during apnoeas (stages $\left.1-2\right) \%$ & $\begin{array}{l}3.5 \pm 0.58 \\
(1.6-7.8)\end{array}$ & $\begin{array}{l}5.7 \pm 1.39 \\
(1.3-13.3)\end{array}$ & $\begin{array}{l}5.6 \pm 1.34 \\
(1.5-16.9)\end{array}$ \\
\hline Duration of apnoeas (stages 1-2) s & $\begin{array}{c}19.8 \pm 1.31 \\
(15-26)\end{array}$ & $\begin{array}{l}22.2 \pm 1.85 \\
(17-32)\end{array}$ & $\begin{array}{c}27.4 \pm 2.71 \\
(15-43)\end{array}$ \\
\hline
\end{tabular}

Results are presented as mean \pm SEM (range). $\mathrm{Sa}_{\mathrm{a}} \mathrm{O}_{2}$ : arterial oxygen saturation; TST: total sleep time. $\mathrm{Sa}_{\mathrm{a}, \mathrm{O}_{2}}$ nadir during apnoeas and $\Delta S_{\mathrm{a}, \mathrm{O}_{2}}$ during apnoeas represent the mean minimal $S_{\mathrm{a}, \mathrm{O}_{2}}$ and the mean degree of desaturation during the 30 selected apnoeas, respectively. 
Table 3. - Blood pressure values during sleep

Group 1

Group 2

Group 3

Age $<50$ yrs normotensive Age $<50$ yrs hypertensive Age $>50$ yrs normotensive

Subjects $n$

10

$114 \pm 2.7$

13.5

Within-individual SD $\mathrm{mmHg}$

Individual coefficient of variation \%

DBP $\mathrm{mmHg}$

Within-individual SD $\mathrm{mmHg}$

Individual coefficient of variation $\%$
11.6

$67 \pm 2.0$

9.1

13.1

8
$150 \pm 5.6^{* * *}$
$21.5^{*}$
15.1
$90 \pm 3.7^{* * *}$
$14.9^{* *}$
17.7

$121 \pm 5.7$

15.2

12.3

$67 \pm 4.8$

9.8

14.2

SBP: systolic blood pressure; DBP: diastolic blood pressure. SBP and DBP values are given as mean \pm SEM of individual values obtained during total sleep time. Within-individual SD represents the square root of pooled within-individual variances for SBP and DBP. Individual coefficients of variations are given as means for the group. $*: p<0.05 ; * *: p<0.01 ; * * *: p<0.001$, significantly different from group 1.

were significantly larger in subjects with untreated hypertension than in normotensive subjects (fig. 2), and correlated positively with daytime SBP (DBP) values obtained using a standard sphygmomanometer when all the subjects aged $<50$ yrs (groups 1 and 2 ) were pooled together $(\mathrm{p}<0.01, \mathrm{r}=0.59)$. In these subjects (groups 1 and 2), the mean amplitude of apnoea-related SBP elevations did not correlate with either the average value of minimal $S \mathrm{a}, \mathrm{O}_{2}$ or $\Delta \mathrm{Sa}_{\mathrm{a}} \mathrm{O}_{2}$ during apnoeas ( $\mathrm{p}=0.19$ and 0.24 , respectively), or the mean duration of apnoeas $(\mathrm{p}=0.31)$. However, the two hypertensive subjects with the most profound desaturations (minimal $\mathrm{Sa}, \mathrm{O}_{2}<75 \%$ ) also had the highest values of apnoea-related BP elevations, suggesting that the latter could be influenced by the severity of hypoxaemia. Nevertheless, when these two subjects were excluded, the average value of apnoea-related SBP (DBP) elevations remained significantly higher in the group of hypertensive subjects without severe desaturation (mean minimal $\mathrm{Sa}_{\mathrm{a}} \mathrm{O}_{2}$ at apnoea termination: $90.3 \pm 1.44$ versus $91.2 \pm 1.00 \%$ in normotensives, NS) than in the normotensives $(44.7 \pm 4.06$ versus $30.7 \pm 2.14 \mathrm{mmHg}$, respectively, $\mathrm{p}<0.01)$. Neither systolic nor diastolic apnoea-related BP elevations were significantly correlated with age.

\section{Blood pressure variability during sleep}

Within-individual SD of beat-by-beat SBP and DBP values during sleep was also significantly increased in group 2 when compared to group 1 (table 3 ). It is worth noting that, during stages $1-2$, the SD of the distribution of SBP (DBP) variations according to their amplitude was strongly correlated with the value of apnoea-related SBP (DBP) elevations (fig. 3). When assessed over the TST, this index of shortterm variability of BP was also significantly higher in subjects with untreated hypertension than in normotensive subjects of similar age (fig. 4), but did not differ between the two normotensive groups of different age.

When all the subjects aged $<50$ yrs (groups 1 and 2) were considered, the SD value of the distribution of SBP (DBP) variations during TST were positively correlated with the daytime SBP (DBP) value $(\mathrm{p}<0.007, \mathrm{r}=0.60)$ and the average SBP (DBP) value during TST, and negatively correlated with the mean value of $S \mathrm{a}, \mathrm{O}_{2}$ during sleep $(\mathrm{p}<0.01, \mathrm{r}=-0.72)$. However, when only the subjects with a mean $\mathrm{Sa}_{\mathrm{a}} \mathrm{O}_{2}$ during sleep of $>90 \%$ were considered (excluding two hypertensive subjects), the SD values of the distribution of SBP or DBP variations were still significantly higher in hypertensive than in normotensive subjects (SD of systolic variations: $17.9 \pm 2.28$ versus $11.1 \pm 0.73 \mathrm{mmHg}$,

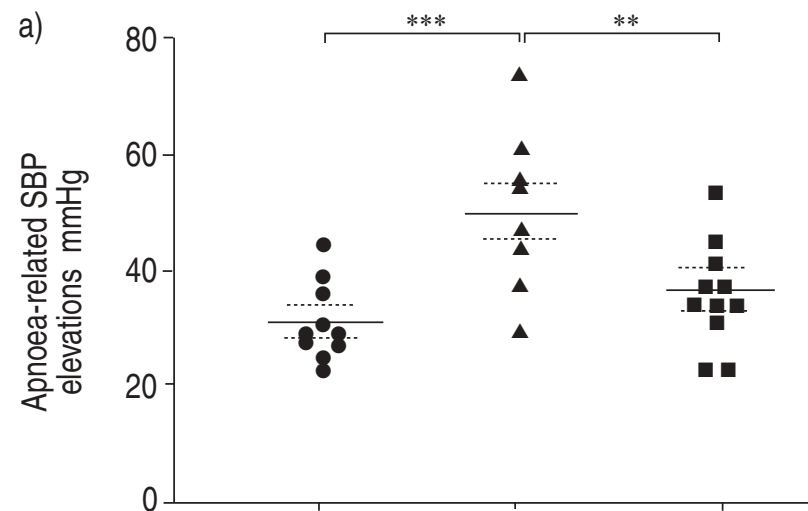

b)

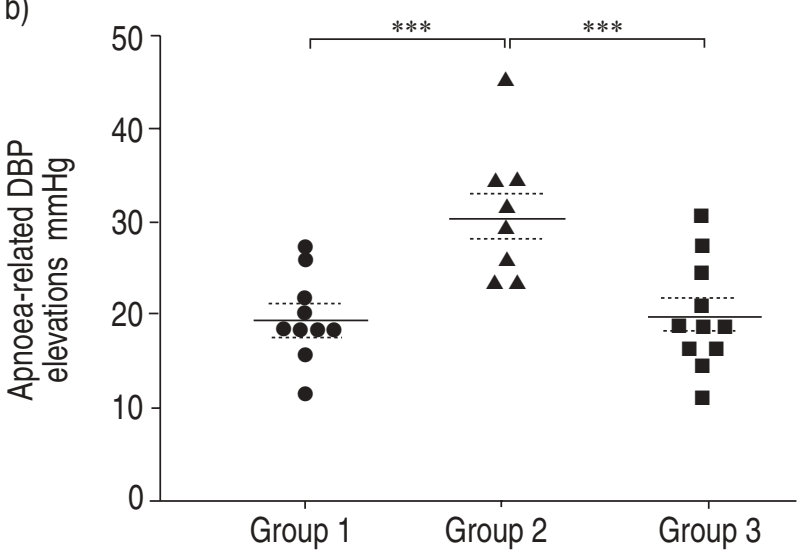

Fig. 2.-Individual values of apnoea-related systolic blood pressure (SBP) and diastolic blood pressure (DBP) elevations during sleep stages 1-2. Data are shown for individual patients and as average values for the group as a whole (solid horizontal lines) \pm SEM (dotted horizontal lines). $* *: p<0.01 ; * * *: p<0.001$. 

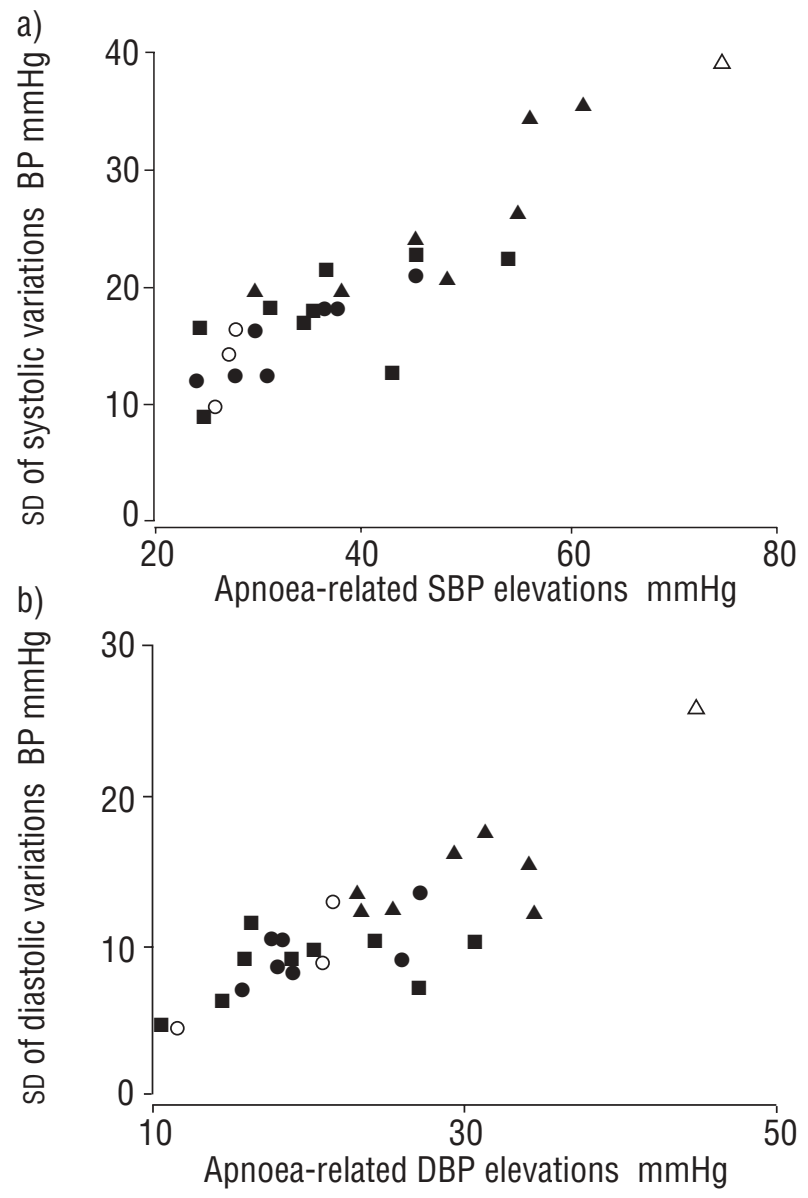

Fig. 3.-Correlation between individual values of a) apnoearelated systolic blood pressure $(\mathrm{SBP})(\mathrm{r}=0.89, \mathrm{p}<0.001)$ or $\mathrm{b}) \mathrm{dia}-$ stolic blood pressure (DBP) $(\mathrm{r}=0.83, \mathrm{p}<0.001)$ elevations and the SD of the distribution of systolic or diastolic variations during sleep stages 1 and 2 in the three groups of obstructive sleep apnoea syndrome (OSAS) patients. 0 : normotensive patients, aged $<50$ yrs; $\boldsymbol{\Delta}$ : hypertensive patients, aged $<50$ yrs; $\boldsymbol{\square}$ : normotensive patients, aged $>50$ yrs. Open symbols: females; closed symbols: males.

respectively, $\mathrm{p}<0.001$; $\mathrm{SD}$ of diastolic variations: $13.2 \pm$ 1.05 versus $9.3 \pm 0.85 \mathrm{mmHg}$, respectively, $\mathrm{p}<0.05$ ).

\section{Discussion}

The major finding of the present study was that systemic HT was associated with greater sleep-apnoea related variability of BP. The amplitude of apnoearelated $\mathrm{BP}$ elevations and the SD of the distribution of all $\mathrm{BP}$ variations according to their amplitude, which was used as a computerised index of short-term variability of BP during sleep, were both markedly increased in hypertensive subjects with OSAS when compared to normotensives. In contrast, aging only minimally, and not significantly, affected $\mathrm{BP}$ variability during sleep in apnoeic patients. From a methodological point of view, this study also demonstrated that the SD of the distribution of all BP variations according to their amplitude, a parameter which can a)
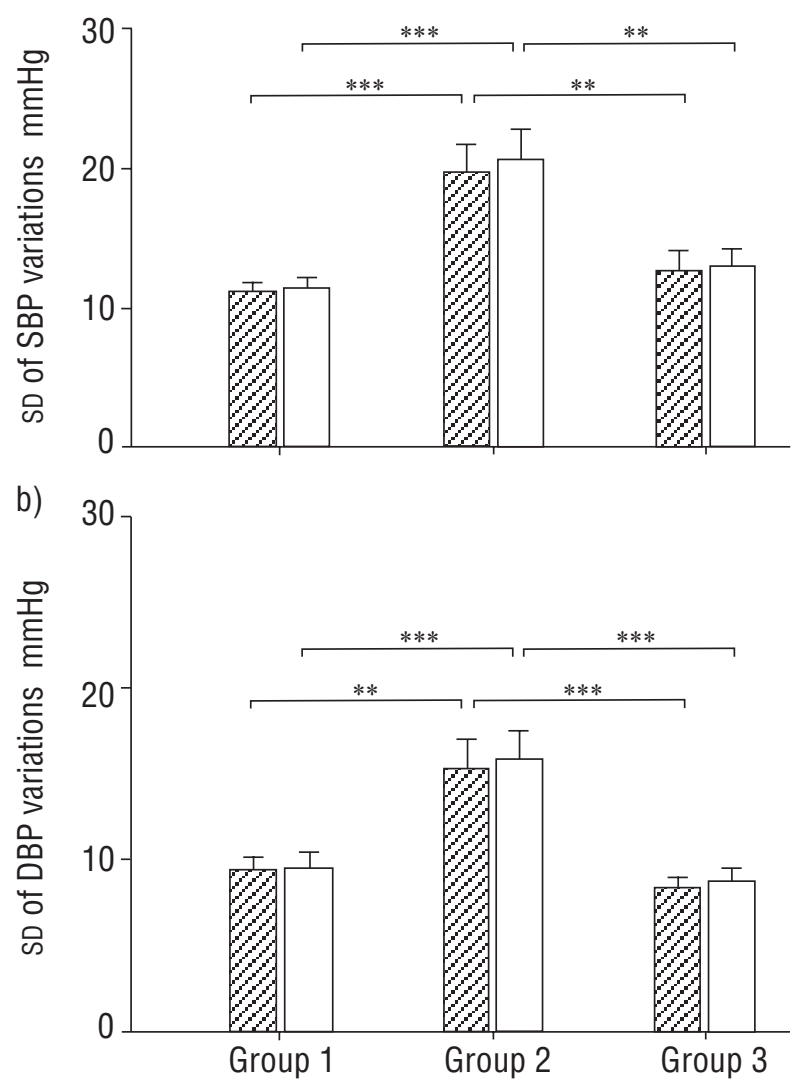

Fig. 4.-SD of the distribution of all a) systolic blood pressure (SBP) and b) diastolic blood pressure (DBP) variations during total sleep time $(\mathbb{Z})$ and sleep stages 1 and $2(\square)$ in the three groups of obstructive sleep apnoea syndrome patients. Group 1: normotensive patients, aged $<50$ yrs; group 2: hypertensive patients, aged $<50$ yrs; group 3: normotensive patients, aged $>50$ yrs. Results are presented as mean \pm SEM. ${ }^{* *}: \mathrm{p}<0.01 ; * * *: \mathrm{p}<0.001$.

be easily computed during sleep studies, is a valuable index of apnoea-related BP elevations.

The present study population comprised exclusively of patients with moderate-to-severe OSAS, who were free of cardiovascular medication. Normotensive and hypertensive OSAS patients aged $<50$ yrs were comparable in age, body masss index (BMI), AHI and arousal index and sleep structure. This ruled out several confounding factors that could influence BP variability such as obesity, aging and sleep fragmentation, all of which have been shown to be associated with an increase in sympathetic drive [11, 16]. Nocturnal beat-by-beat BP was recorded with a Finapres system synchronised with polysomnography, a noninvasive technique that has been shown to be an accurate method for monitoring fast BP changes [17] and induces only minimal sleep disturbance [5, 7]. When compared with measurements from a brachialartery catheter, the Finapres may slightly overestimate SBP and its variability [18]. However, as this overestimation is not related to BP level, the Finapres may be satisfactory for comparing BP variability between subjects.

The amplitude of BP elevations at the termination of obstructive respiratory events was markedly 
increased in the hypertensive group and was correlated with daytime as well as night-time BP levels. The apnoeas or hypopnoeas used for measurements were selected randomly during stages 1 or 2 of NREM sleep and ended with a typical cortical EEG arousal, thus ruling out differences in sleep stage $[7,12,19]$ or in the type and duration of EEG arousal [20] that might influence the amplitude of apnoea-related BP surges. The degree of arterial hypoxaemia is another factor that might influence systemic BP during apnoea [21]. Studying intra-individual correlations between BP and $\mathrm{Sa}_{\mathrm{a}} \mathrm{O}_{2}$, Shepard [22] previously showed that the degree of desaturation modulated the surge in pressure at apnoea termination, accounting for $\sim 30 \%$ of its amplitude. In contrast, the present study examined interindividual correlations and found that the amplitude of apnoea-related SBP (DBP) elevation was not significantly correlated with $\mathrm{Sa}_{\mathrm{a}} \mathrm{O}_{2}$ nadir at the end of apnoea. This may be explained by the fact that all of the study subjects, with the exception of two (belonging to the hypertensive group), had only mild-tomoderate nocturnal oxygen desaturations $\left(\mathrm{Sa}_{\mathrm{a}} \mathrm{O}_{2}\right.$, nadir $>85 \%$ ). Moreover, the average value of apnoearelated SBP (DBP) elevation was still significantly higher in the subgroup of hypertensive subjects without severe desaturation than in the normotensive subjects. These observations argue against the possibility that the greater BP fluctuations observed in the hypertensive population could simply be a reflection of the more profound hypoxaemia. However, it is likely that the severity of hypoxemia might in some way influence the amplitude of apnoea-related BP elevation.

In the present study, the SD of beat-by-beat SBP and DBP values during TST, an estimate of short- and long-term variability of BP, was significantly increased in the hypertensive compared with the normotensive apnoeics. MANCIA et al. [23] previously reported that the absolute variability of BP was increased during sleep in subjects with mild and severe essential HT. Since $\sim 30 \%$ of patients with essential HT may be expected to have OSAS [24, 25], it is likely that their study population included both apnoeic and nonapnoeic subjects. The present results showed that the SD of the distribution of all-night SBP (DBP) variations according to their amplitude was also markedly increased in hypertensive subjects, and was significantly correlated with both the daytime SBP (or DBP) value and mean SBP (or DBP) during sleep. This computerised index was specifically designed to assess BP variability during sleep in patients with sleepdisordered breathing, as it can be computed even during nonstationary periods of varying durations. It reflected short-term variability of BP since all the BP changes computed lasted $<20 \mathrm{~s}$ and were influenced by sleep fragmentation $[12,26]$. However, a difference in OSAS severity could not account for the difference between the normotensive and hypertensive groups as both populations had comparable AHI, arousal index and sleep structure. It was found that the SD of the distribution of SBP (DBP) variations was significantly correlated with mean $\mathrm{Sa}_{\mathrm{a}} \mathrm{O}_{2}$ during sleep, suggesting that hypoxaemia could influence short-term variability of BP during sleep in OSAS. However, this index was also significantly higher in the subgroup of hypertensive subjects without severe nocturnal hypoxemia (mean $\mathrm{Sa}_{\mathrm{a}} \mathrm{O}_{2}>90 \%$ ) than in normotensive subjects with comparable nocturnal $\mathrm{Sa}_{2} \mathrm{O}_{2}$. Therefore, hypoxaemia alone was probably not sufficient to explain the greater short-term variability of BP in the hypertensive group.

As systemic hypertension is very common in obstructive sleep apnoea syndrome the present results, highlighting as they do the greater short-term variability of blood pressure during sleep in apnoeic patients with untreated systemic hypertension, may have important clinical relevance. Since excessive blood-pressure variability has been linked to targetorgan damage, sleep apnoea patients with systemic hypertension might be at particular risk. The computation of the SD of the distribution of blood-pressure variations during sleep, a computerised index of shortterm blood-pressure variability with a good correlation with the amplitude of apnoea-related blood-pressure elevations, might be helpful in appreciating the effect of obstructive sleep apnoea syndrome treatment or antihypertensive medication on nocturnal bloodpressure variability in hypertensive patients with sleep apnoea.

Acknowledgements. The authors would like to thank M. Berkani, M. Herman, M. Essalhi and G. M'Roue for their helpful technical assistance.

\section{References}

1. Hla KM, Young TB, Bidwell T, Palta M, Skatrud JB, Dempsey J. Sleep apnea and hypertension. A population-based study. Arch Int Med 1994; 120: 382-388.

2. Young T, Peppard P, Palta M, et al. Population-based study of sleep-disordered breathing as a risk factor for hypertension. Arch Int Med 1997; 157: 1746-1752.

3. Peppard PE, Young T, Palta M, Skatrud J. Prospective study of the association between sleep-disordered breathing and hypertension. N Engl JMed 2000; 342: $1378-1384$.

4. Lavie P, Herer P, Hoffstein V. Obstructive sleep apnoea syndrome as a risk factor for hypertension: population study. BMJ 2000; 320: 479-482.

5. Hedner J, Ejnell H, Sellgren J, Hedner T, Wallin G. Is high and fluctuating muscle nerve sympathetic activity in sleep apnea syndrome of pathogenetic importance for the development of hypertension? $J$ Hypertens 1988; 6: S529-S531.

6. Narkiewicz K, Montano N, Cogliati C, Van De Borne PJH, Dyken ME, Somers VK. Altered cardiovascular variability in obstructive sleep apnea. Circulation 1998; 98: 1071-1077.

7. Somers VK, Dyken ME, Clary MP, Abboud FM. Sympathetic neural mechanisms in obstructive sleep apnea. J Clin Invest 1995; 96: 1897-1904.

8. Grassi G, Cattaneo BM, Seravalle G, Lanfranchi A, Mancia G. Baroreflex control of sympathetic nerve activity in essential and secondary hypertension. Hypertension 1998; 31: 68-72. 
9. Parati G, Pomidossi G, Albini F, Malaspina D, Mancia G. Relationship of 24-hour blood pressure mean and variability to severity of target-organ damage in hypertension. J Hypertens 1987; 5: 93-98.

10. Frattola A, Parati G, Cuspidi C, Albini F, Mancia G. Prognostic value of 24-hour blood pressure variability. J Hypertens 1993; 11: 1133-1137.

11. Davy KP, Tanaka H, Andros EA, Gerber JG, Seals DR. Influence of age on arterial baroreflex inhibition of sympathetic nerve activity in healthy adult humans. Am J Physiol 1998; 275: H1768-H1772.

12. Leroy M, Van Surell C, Pilliere R, et al. Short-term variability of blood pressure during sleep in snorers with or without apnea. Hypertension 1996; 28: $937-$ 943.

13. Rechtschaffen A, Kales A. A manual of standardized terminology techniques and scoring system for sleep states of human subjects. Publication no. 204. Washington DC, National Institues of Health, 1968.

14. ASDA. EEG arousals: scoring rules and examples. Sleep 1992; 15: 174-184.

15. Staessen J, Fagard R, Lijnen P, Thijs L, Van Hoof R, Amery A. Reference values for ambulatory blood pressure: a meta-analysis. J Hypertens 1990; 8: S57S64.

16. Grassi G. Sympathetic activation in obese normotensive subjects. Hypertension 1995; 25: 560-563.

17. Imholz BPM, Langewouters GJ, Van Montfrans GA, et al. Feasibility of ambulatory, continuous 24-hour finger arterial pressure recording. Hypertension 1993; 21: 65-73.

18. Omboni S, Parati G, Castiglioni P, et al. Estimation of blood pressure variability from 24 hour ambulatory finger blood pressure. Hypertension 1998; 32: 52-58.

19. Somers VK, Dyken ME, Mark AL, Abboud FM. Sympathetic-nerve activity during sleep in normal subjects. N Engl J Med 1993; 328: 303-307.

20. Davies RJO, Belt PJ, Roberts SJ, All NJ, Stradling JR. Arterial blood pressure responses to graded transient arousal from sleep in normal humans. J Appl Physiol 1993; 74: 1123-1130.

21. Leuenberger U, Jacob E, Swerr L, Waravdekar N, Zwillich C, Sinoway L. Surges of muscle sympathetic nerve activity during obstructive apnea are linked to hypoxemia. J Appl Physiol 1995; 79: 581-588.

22. Shepard JW. Hemodynamics in obstructive sleep apnea. In: Fletcher EC, ed. Abnormalities of Respiration During Sleep. Orlando, Grime and Stratton, 1986; pp. 39-62.

23. Mancia G, Ferrari A, Gregorini L, et al. Blood pressure and heart rate variabilities in normotensive and hypertensive human beings. Circ Res 1983; 53: 96104.

24. Kales A, Bixler EO, Cadieux RJ, et al. Sleep apnoea in a hypertensive population. Lancet 1984; 2: 1005-1008.

25. Fletcher EC, DeBehnke RD, Lovoi MS, Gorin AB. Undiagnosed sleep apnea in patients with essential hypertension. Ann Intern Med 1985; 103: 190-195.

26. Planes C, Foucher A, Leroy M, et al. Effect of celiprolol treatment in hypertensive patients with sleep apnea. Sleep 1999; 22: 507-513.

27. Mancia G, Di Rienzo M, Parati G, Grassi G. Sympathetic activity, blood pressure variability and end organ damage in hypertension. J Human Hypertension 1997; 11: Suppl. 1, S3-S8.

28. Parati G, Di Rienzo M, Bertinieri G, et al. G. Evaluation of the baroreceptor heart rate reflex by 24-hour intra-arterial blood pressure monitoring in humans. Hypertension 1988; 12: 214-222.

29. Xie P, McDowell TS, Chapleau MW, Hajduczok G, Abboud FM. Rapid baroreceptor resetting in chronic hypertension. Implications for normalization of arterial pressure. Hypertension 1991; 17: 72-79.

30. Parati G, Di Rienzo M, Bonsignore MR, et al. Autonomic cardiac regulation in obstructive sleep apnea syndrome: evidence from spontaneous baroreflex analysis during sleep. J Hypertens 1997; 15: 16211626. 